\title{
Foreword to Analytic Feminism
}

Traditionally, analytic philosophy is thought to be more of an abstract, technical field of study than the socially engaged Continental or postmodern schools of thought. Fortunately, this perceived image is changing as the discipline is more aware of its previous limitations and broadening its horizon. Matters like gender equality, racism, classism, or agism are now essential issues even in fields such as the philosophy of language or the philosophy of science - both of which were previously known for purely naturalized theoretical and formal approaches. What remained the same during this shift of focus is the signature style of every analytic work: a precise use of language, and the explicit, strict argumentative structure. Analytic feminists are philosophers who think that these methods serve to reach their practical aims.

We would like to contribute to this emerging area of interest with this special issue, proudly presenting the very first mixed-language edition of Elpis. This thematic block contains four original research articles in English, written by young scholars.

Áron Dombrovszki's paper provides a detailed introduction of one of the first positive research programs in analytic feminism, that is, the issue of pornography and silencing. The article not only introduces Rae Langton's theses and the debate surrounding it, but it also provides valuable contextual information to make the subject more accessible to all. In Dombrovszki's view, Langton's landmark article was the start of a new way of thinking in feminist philosophy; her methods were more important than the interpretation she presented.

Bernd Prien's article is loosely connected to this, as he considers different accounts of the analysis of hate speech using John Austin's speech act theory. Even though there is an agreement between scholars about how hate speech constitutes subordination, the exact details of this process are subject to debate. Prien suggests another approach mainly relying on Rebecca Kukla's insights. According to his proposal, it is best to understand hate speech and slurs as interpellations, such that their usage calls upon the hearer to play a derogative social role.

In her paper, Anna Réz examines the eternal philosophical issue of abortion from a feminist point of view. She focuses on the mainstream defense of abortion, relying on bodily autonomy, most famously presented in Judith Jarvis Thomson's book. Réz agrees with the contemporary critics of the Thomsonian reasoning, as it leads to some unfortunate theoretical consequences. Nevertheless, she argues that with practical aims in mind, perhaps our chances are better to influence public opinion building on the rights of bodily autonomy. 
Virág Véber's article explores the other side of feminist theories, calling our attention to stereotypes against men. She points out that it is necessary to eliminate biases against both men and women in order to reach gender equality. During this investigation, Véber evokes important concepts for feminist thinking, such as the issue of implicit bias and its harmful effects, or the distinction between hostile and benevolent sexism.

Finally, we would like to thank our reviewers for their essential help and assistance.

Áron Dombrovszki 